\title{
KEANEKARAGAMAN JENIS POHON SEBAGAI SALAH SATU INDIKATOR KESEHATAN HUTAN LINDUNG (Studi Kasus di Kawasan Hutan Lindung yang Dikelola oleh HKm Beringin Jaya)
}

\section{Tree diversity as an indicator of protected Forest health(Case Study in Protected Forest Area Managed by HKm Beringin Jaya)}

\author{
Rahmat Safe'i, Hari Kaskoyo, Arief Darmawan, Fansuri Fikri Haikal \\ Jurusan Kehutanan Universitas Lampung, Bandar Lampung \\ Jl. Prof. Sumantri Brojonegoro No.1 Bandar Lampung 35145 \\ Email: rahmat.safei@fp.unila.ac.id
}

Diterima : 18/08/2020, Direvisi : 25/09/2020, Diterbitkan 01/03/2021

\begin{abstract}
Protection forest becomes a forest area with the main function as protection of life support systems. The health condition of protected forests has a great influence on the environment of the ecosystem. It is important to assess the health of protected forests in view of their main function. Thus to determine the health condition of the forest, one indicator that can be used is tree biodiversity. Biodiversity is the richness of life found on earth. Assessment of biodiversity indicators is very necessary to do because it is sensitive to changes, ecological system indicators, spatial heterogeneity, temporal, and and the order in the food chain. This study aims to determine the diversity of tree species in protected forest areas managed by HKm Beringin Jaya as an indicator of forest health assessment. The study was conducted using the Forest Health Monitoring (FHM) method. The results showed that the final value of forest health status with indicators of biodiversity (tree species diversity) in the protected forest area managed by HKm Beringin Jaya was in the good category of 50\% in cluster plots (2, 5 and 6) and bad by $50 \%$ on cluster plots (1, 3 and 4 ), thus showing that the protected forest area managed by HKm Beringin Jaya has a fairly healthy (stable) condition with a moderate category.
\end{abstract}

Keywords: protected forest, biodiversity, community forest, forest health status

\begin{abstract}
ABSTRAK
Hutan lindung menjadi suatu kawasan hutan dengan fungsi pokok sebagai perlindungan sistem penyangga kehidupan. Kondisi kesehatan hutan lindung memiliki pengaruh yang besar terhadap lingkungan ekosistemnya. Penilaian kesehatan hutan lindung penting dilakukan melihat fungsi utamanya. Dengan demikian untuk mengetahui kondisi kesehatan hutannya, salah satu indikator yang dapat digunakan adalah biodiversitas/keanekaragaman hayati. Keanekaragaman hayati merupakan kekayaan hidup yang terdapat di bumi. Penilaian indikator keanekaragaman hayati sangat butuh untuk dilakukan karena sensitif terhadap perubahan, indikator sistem ekologi, heterogenitas spasial, temporal, dan urutan dalam rantai makanan. Penelitian ini bertujuan untuk mengetahui keanekaragaman jenis pohon di kawasan hutan lindung yang dikelola oleh HKm Beringin Jaya sebagai salah satu indikator penilaian kesehatan
\end{abstract}


hutan. Penelitian dilakukan dengan menggunakan metode Forest Health Monitoring (FHM). Hasil penelitian menunjukkan bahwa nilai akhir status kesehatan hutan dengan indikator keanekaragaman hayati (keanekaragaman jenis pohon) di kawasan hutan lindung yang dikelola oleh $\mathrm{HKm}$ Beringin Jaya berada pada kategori baik sebesar $50 \%$ (pada klaster plot 2, 5 dan 6) dan kategori buruk sebesar $50 \%$ (pada klaster plot 1, 3 dan 4). Hasil penelitian ini mengindikasikan bahwa kawasan hutan lindung yang dikelola oleh HKm Beringin Jaya memiliki kondisi cukup sehat (stabil) dengan kategori sedang.

Kata kunci: biodiversitas, hutan kemasyarakatan, hutan lindung, status kesehatan hutan

\section{PENDAHULUAN}

Hutan lindung merupakan kawasan hutan negara dengan fungsi utama sebagai perlindungan sistem penyangga kehidupan untuk dapat mengatur tata air, mencegah banjir, mengendalikan erosi, mencegah intrusi air laut, dan memelihara kesuburan tanah (Undang-undang No. 41 tahun 1999 tentang kehutanan). Melalui sistem perhutanan sosial pemerintah membentuk skema hutan kemasyarakatan $(\mathrm{HKm})$. Salah satu hutan negara yang ditetapkan sebagai areal kerja HKm yaitu hutan lindung (Winarni et al., 2016). Salah satu $\mathrm{HKm}$ di provinsi Lampung yaitu HKm Beringin Jaya yang pengelolaannya berada di kawasan hutan lindung dengan berbagai macam keanekaragaman jenis pohon di dalamnya. Melihat fungsi utama dari hutan lindung dan pengelolaan di dalamnya maka penting untuk dilakukan penilaian kesehatan hutannya.

Keanekaragaman hayati atau biodiversitas merupakan hal yang penting bagi kehidupan. Biodiversitas berperan menjadi indikator dan sarana dari sistem ekologi serta perubahan spesies. Biodiversitas di dalamnya juga mencakup kekayaan spesies dan ekosistem yang kompleks sehingga dapat mempengaruhi komunitas organisme, stabilitas dan perkembangan ekosistem (Rahayu et al., 2017).

Indikator keanekaragaman jenis pohon dalam biodiversitas hutan telah diidentifikasi sebagai kriteria keberlanjutan ekosistem hutan. Keanekaragaman jenis pohon berguna sebagai ukuran kesehatan hutan. Menurut Safe'i et al. (2018), kesehatan hutan dapat menjadi gambaran bagi kondisi suatu ekosistem hutan yang dapat menjalankan fungsi utama dengan baik. Indikator keanekaragaman jenis pohon merupakan salah satu indikator ekologis kunci bagi kesehatan hutan hujan tropis Indonesia. Menurut Safe'i et al. (2015); Supriyanto et al. (2001), ada empat indikator ekologis kunci bagi kesehatan hutan hujan tropis Indonesia, yakni: produktivitas, vitalitas, kualitas tapak, dan biodiversitas (keanekaragaman jenis). Penilaian indikator keanekaragaman jenis sangat penting untuk dilakukan agar dapat diketahui tingkat kelenturan suatu jenis pada ekosistem hutan tertentu dengan mengetahui komposisi flora yang terdapat di dalamnya (Safe'i et al., 2018).

Salah satu indikator biodiversitas adalah keanekaragaman jenis pohon. Makin besar jumlah keanekaragaman jenis pohon, maka akan semakin besar biodiversitasnya. Makin tinggi jumlah jenis pohon dan nilai keanekaragaman jenis pohon pada suatu area akan meningkatkan pula keragaman fungsi ekologi (Wulandari, 2010).

Pengelolaan oleh HKm Beringin Jaya perlu dilakukan penelitian terkait kesehatan hutannya karena berada di kawasan hutan lindung. Tingkat biodiversitas dengan indikator keanekaragaman jenis pohon berkaitan erat dengan tingkat kestabilan ekologi pada suatu ekosistem. Dengan demikian, sangat penting dilakukan penelitian untuk mengetahui status kondisi kesehatan hutan lindung dengan menggunakan salah satu indikator ekologis yaitu berdasarkan biodiversitas. 


\section{METODE}

Lokasi penelitian dilakukan pada kawasan hutan lindung yang dikelola oleh HKm Beringin Jaya yang berada di Pekon Margoyoso, Kecamatan Sumberejo, Kabupaten Tanggamus, Provinsi Lampung. Peta lokasi penelitian dapat dilihat pada Gambar 1.

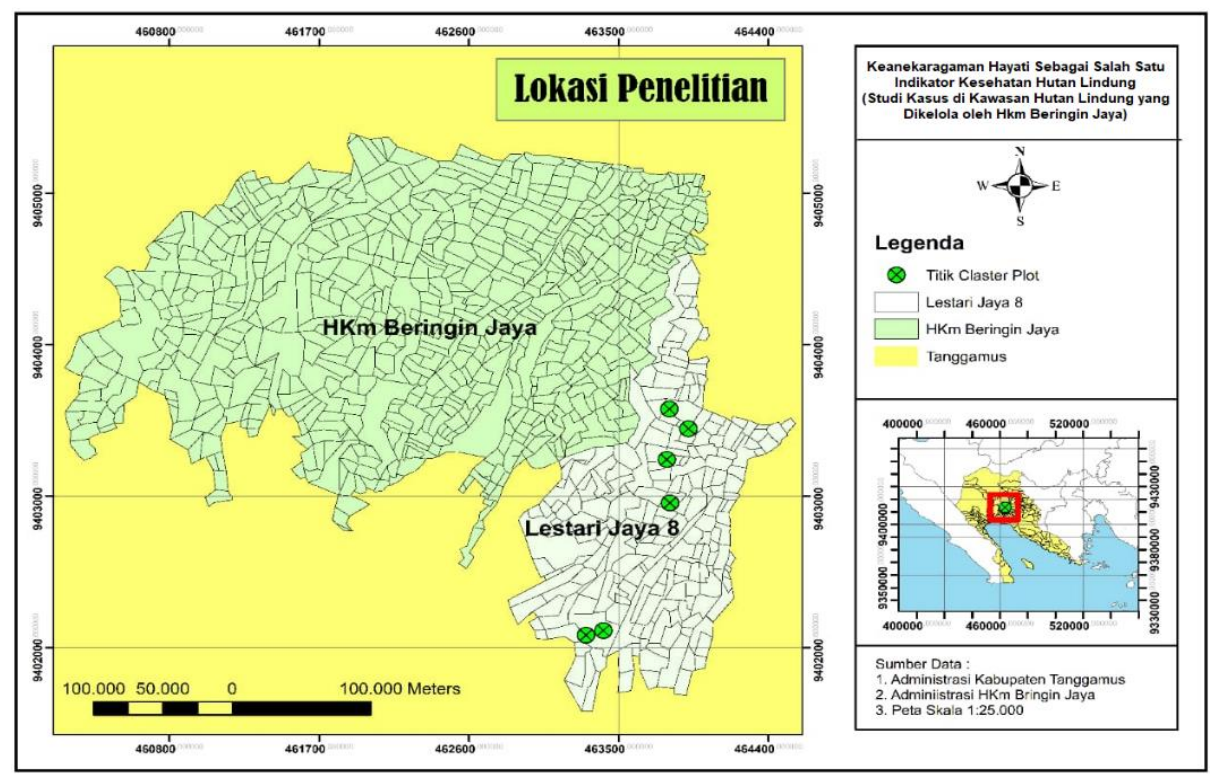

Gambar 1. Peta lokasi penelitian

Figure 1. Map of research location

Alat yang digunakan dalam penelitian terdiri dari: tally sheet, kompas, paku pines, paralon, GPS, spidol permanen, label plastik, meteran, pita meter $(150 \mathrm{~cm})$, magic card (kartu skala kerapatan dan transparasi tajuk pohon) dan kamera digital. Objek dalam penelitian ini adalah klaster plot Forest Health Monitoring (FHM) di kawasan hutan lindung yang dikelola oleh $\mathrm{HKm}$ Beringin Jaya.

Klaster-plot merupakan desain plot contoh yang digunakan dalam melakukan pembuatan plot ukur kesehatan hutan. Pembuatan plot ukur kesehatan hutan ini didasarkan pada desain klaster-plot FHM (Mangold, 1997; USDA-FS, 1999; Safe'i et al., 2015). Luas total klaster-plot pengamatan yaitu 2,4 ha dengan jumlah klaster plot yang dibuat yaitu 6 klaster-plot. Desain klaster plot FHM kesehatan hutan dalam pengelolaan HKm Beringin Jaya memiliki kriteria pembuatan klaster plot FHM (Safe'i et al., 2015), yaitu

a. Klaster plot terdiri dari masing-masing 4 annular plot, subplot dan mikroplot.

b. Mempunyai annular plot berupa lingkaran dengan jari-jari 17,95 m, subplot dengan jari-jari 7,32 $\mathrm{m}$ dan mikroplot dengan jari-jari 2,07 m.

c. Penentuan titik pusat setiap plot dijelaskan sebagai berikut:

1. Titik pusat subplot 1 (satu) merupakan titik pusat bagi keseluruhan plot.

2. Titik pusat sublot 2 (dua) terletak pada arah $0^{\circ}$ atau $360^{\circ}$ dari titik pusat subplot 1 (satu).

3. Titik pusat subplot 3 (tiga) terletak pada arah $120^{\circ}$ dari titik pusat subplot 1 (satu)

4. Titik pusat subplot 4 (empat) terletak pada arah $240^{\circ}$ dari titik pusat subplot 1 , dengan masing-masing jarak antara titik pusat subplot adalah 36,6 meter.

\section{Pengolahan dan Analisis Data}

Pengolahan dan analisis data dilakukan terhadap hasil pengukuran keanekaragaman jenis pohon di lokasi penelitian. Tingkat keanekaragaman jenis ditentukan menggunakan rumus Shannon-Whiener index H' (Soerianegara dan Indrawan, 2005). 
Keterangan:

$$
H^{\prime}=\sum p i \ln p i
$$

$\mathrm{H}^{\prime}=$ Shannon-Wiener Index

$\mathrm{pi}=\mathrm{ni} / \mathrm{N}$

$\mathrm{ni}=$ jumlah individu jenis ke $\mathrm{i}$

$\mathrm{N}=$ jumlah individu seluruh jenis

Kriteria nilai indeks keanekaragaman sebagai berikut.

$\mathrm{H}^{\prime}<1$ (komunitas vegetasi dengan kondisi lingkungan kurang stabil); $1<\mathrm{H}^{\prime}=3 \backslash \mathrm{d}$ engan kondisi lingkungan sangat stabil)

\section{Penilaian Kesehatan Hutan}

Penilaian kesehatan hutan menggunakan indikator keanekaragaman hayati dengan indikator keanekaragaman jenis pohon. Data yang diperoleh digunakan untuk mengetahui status kesehatan hutan yang diukur berdasarkan FHM. Rumus yang digunakan untuk nilai akhir kesehatan hutan (Safe'i et al., 2015), adalah:

$$
\mathrm{NKH}=\mathrm{NT} \times \mathrm{NS}
$$

Keterangan: $\mathrm{NKH}=$ nilai akhir kondisi kesehatan hutan; NT = nilai tertimbang indikator keanekaragaman jenis pohon; NS = nilai skor indikator keanekaragaman jenis pohon.

\section{HASIL DAN PEMBAHASAN}

Pengelolaan hutan kemasyarakatan memiliki prinsip untuk mendapatkan manfaat sumber daya hutan secara optimal dan adil dengan pengelolaan yang lestari. Pemantauan hutan penting untung diketahui dalam melakukan suatu pengelolaan HKm. Penilaian indikator biodiversitas sangat butuh untuk dilakukan agar dapat diketahui tingkat kelenturan suatu jenis pada ekosistem hutan tertentu dengan mengetahui komposisi flora yang terdapat di dalamnya (Safe'i et al., 2018). Tingkat biodiversitas berbanding lurus dengan tingkat kelenturan, dimana semakin tinggi tingkat biodiversitas yang dimiliki dalam suatu hutan akan meningkatkan tingkat kelenturan hutan (Safe'i et al., 2019)

Safe'i dan Tsani (2016) menyatakan salah satu komponen hayati yang ada di dalam hutan adalah kumpulan dari tetumbuhan atau pohon. Keanekaragaman hayati hutan merupakan seluruh makhluk hidup yang berada di hutan, maka keanekaragaman pohon merupakan semua jenis pepohonan yang ada di dalam hutan. Hutan lindung secara alami memiliki berbagai macam jenis tanaman (Naisumu et al., 2018). Keseimbangan ekologi akan tetap terjaga jika ekosistem hutan masih memiliki keanekaragaman jenis tanaman yang tinggi di dalamnya (Safe'i et al., 2018).

Indikator biodiversitas yang digunakan adalah indeks keanekaragaman jenis pohon dengan rumus Shannon-Wiener index. Menurut Nahlunnisa et al. (2016); Nuraina et al. (2018), indeks keanekaragaman jenis merupakan indeks yang menyatakan struktur komunitas dan dengan rumus Shannon-Wiener index dapat diketahui tingkat keragaman jenis yang ada pada suatu ekosistem. Indikator biodiversitas dipilih karena mudah mengalami interaksi dengan lingkungan serta dapat dijadikan indikator dalam melakukan penilaian kesesehatan hutan (Safe'i et al., 2018).

\section{Penilaian Keanekaragaman Jenis Pohon}

Penilaian kesehatan hutan dengan indikator ekologis yaitu biodiversitas dilakukan dengan pengukuran keanekaragaman jenis pohon menggunakan rumus Shannon-Wiener index. Pengukuran keanekaragaman jenis pohon dilakukan terhadap pohon yang berada di dalam annular plot. Indeks keanekaragaman jenis pohon merupakan indeks yang 
menyatakan struktur komunitas, sehingga semakin baik indeks keragaman jenis maka suatu ekosistem akan semakin stabil (Nahlunnisa et al., 2016; Nuraina et al., 2018). Nilai biodiversitas tertinggi adalah 1,53 pada klaster plot 5 dan terendah adalah 0,33 yang berada pada klaster plot 4. Hasil penilaian indeks keanekaragaman jenis pohon pada masing-masing klaster plot dapat dilihat pada Tabel 1.

Tabel 1. Nilai Keanekaragaman Jenis Pohon Masing-Masing Klaster Plot

Table 1. Diversity Value of Tree Species for each Plot Cluster

\begin{tabular}{cc}
\hline Klaster Plot & H' $^{\prime}$ \\
\hline 1 & 0,77 \\
2 & 1,41 \\
3 & 0,39 \\
4 & 0,33 \\
\hline 5 & 1,53 \\
6 & 1,38 \\
\hline
\end{tabular}

Sumber: Data Primer (2020).

Kawasan hutan lindung yang dikelola oleh HKm Beringin Jaya harus melakukan pengelolaan secara lestari dengan tidak mengubah status dan fungsi Kawasan hutan. Seperti fungsinya hutan lindung berperan sebagi pelindung kawasan air, pencegah banjir, pencegah erosi dan pemeliharaan kesuburan tanah. Penilaian kesehatan hutan di kawasan hutan lindung yang dikelola oleh $\mathrm{HKm}$ Beringin Jaya dapat dinilai melalui keanekaragaman jenis pohon yang diidentifikasikan sebagai kriteria keberlanjutan ekosistem hutan. Penilaian biodiversitas pada penelitian ini menggunakan indeks keanekaragaman atau diversity index dengan rumus Shannon-Weiner Index (Soerianegara dan Indrawan, 2005).

Setelah dilakukan perhitungan pada 6 klaster plot diperolehlah nilai keanekaragaman pada setiap klaster plot, seperti pada Tabel 1. Nilai $\mathrm{H}^{\prime}$ terendah dan nilai $\mathrm{H}^{\prime}$ tertinggi terdapat di klaster plot 4 (empat) dan klaster plot 5 (lima) yaitu 0,33 dan 1,53. Menurut Magguran (1988) besaran $H^{\prime}<1,5$ menunjukkan keanekaragaman jenis tergolong rendah, jika $H^{\prime}=1,5-3,5$ menunjukkan keanekaragaman jenis tergolong sedang dan jika $H^{\prime}>3,5$ menunjukkan keanekaragaman jenis tergolong tinggi. Berdasarkan hal tersebut maka klaster plot pada $\mathrm{HKm}$ Beringin Jaya menunjukkan tingkat keanekaragaman jenis tergolong rendah pada klaster plot 4 dengan nilai $\mathrm{H}^{\prime} 0,33$ dan tergolong sedang pada klaster plot 5 sedang dengan nilai $\mathrm{H}^{\prime}=1,53$.

Berdasarkan Shannon-Whiener (Soerianegara dan Indrawan, 2005),jika nilai H' $<1$, maka komunitas vegetasi dengan kondisi lingkungan kurang stabil; jika nilai $\mathrm{H}^{\prime}$ antara 1-2, maka komunitas vegetasi dengan kondisi lingkungan stabil; jika nilai $\mathrm{H}^{\prime}>2$, maka komunitas vegetasi dengan kondisi lingkungan sangat stabil. Berdasarkan hal tersebut maka klaster plot 2, 5 dan 6 menunjukkan komunitas vegetasi dengan kondisi lingkungan yang stabil dan klaster plot 1, 3 dan 4 menunjukkan komunitas vegetasi dengan kondisi lingkungan yang kurang stabil karena $\mathrm{H}^{\prime}$ yang diperoleh $<1$.

Berdasarkan hasil penelitian dari keseluruhan 6 klaster plot diperoleh total jenis pohon sebanyak 34 spesies. Berikut ini data keanekaragaman jenis pohon pada klaster plot yang berada di kawasan hutan lindung yang dikelola oleh HKm Beringin Jaya dapat dilihat pada Tabel 2.

Tabel 2. Data Keanekaragaman Jenis Pohon

Table 2. Data on Tree Species Diversity

\begin{tabular}{lllll}
\hline No & Jenis Pohon & Nama Latin & Jumlah & Plot \\
\hline 1 & Alpukat & Persea americana & 10 & $3,4,5$ \\
2 & Bayur & Pterospermum javanicum & 4 & $5 \& 6$ \\
3 & Cempaka Kuning & Magnolia champaca & 4 & 2 \\
\hline
\end{tabular}




\begin{tabular}{lllll}
\hline 4 & Cempaka Telor & Magnolia lilifera & 1 & 2 \\
5 & Cengkeh & Syzygium aromaticum & 1 & 1 \\
6 & Flamboyan & Delonix Regia & 1 & 2 \\
7 & Jambon & Neolamarckia cadamba & 8 & 1 \& 2 \\
8 & Jengkol & Archidendron pauciflorum & 3 & 6 \\
9 & Jeruk Hutan & Citrus macroptera & 1 & 1 \\
10 & Kayu Air-air & Jackia ornata & 1 & 2 \\
11 & Kayu Amplas & Ficus ampelas & 1 & 2 \\
12 & Kayu pasang & Quercus sundaica & 2 & 1,2 \\
13 & Kelengkeng Hutan & Dimocarpus longan & 1 & 2 \\
14 & Mahoni & Swietenia macrophylla & 7 & 5 \& 6 \\
15 & Mangga & Mangifera indica & 1 & 5 \\
16 & Medang & Schima wallichii & 10 & 2 \\
17 & Melinjo & Gnetum gnemon & 1 & 6 \\
18 & Meniran & Phyllanthus urinaria & 1 & 2 \\
19 & Meranti Merah & Shorea macrophylla & 2 & 2 \\
20 & Waru Gunung & Hibiscus similis & 3 & 1 \\
21 & Mindi & Melia azedarach & 3 & $5 \& 6$ \\
22 & Nangka & Artocarpus heterophyllus & 1 & 3 \\
23 & Petai & Parkia speciosa & 5 & 5 \\
24 & Petai Cina & Leucaena leucocephala & 9 & 5,6 \\
25 & Randu & Ceiba pentandra & 9 & 5,6 \\
26 & Suren & Toona sureni & 20 & $5 \& 6$ \\
27 & Sengon & Albizia chinensis & 6 & 5 \& 6 \\
28 & Sintuk & Cinnamomum malabatrum & 1 & 1 \\
29 & Sonokeling & Dalbergia latifolia & 34 & $3,4,5$ \\
30 & Tutup Putih & Mallotus paniculatus & 1 & 2 \\
31 & Walik Angin & Mallotus paniculatus & 1 & 2 \\
32 & Wareng & Gmelina arborea & 1 & 5 \\
33 & Waru & Hibiscus tiliaceus & 6 & 6 \\
34 & Merbau & Intsia bijuga & 1 & 2 \\
\hline Jumlah & & 161 & \\
\hline Suma & ber: Data Primer & & & \\
\end{tabular}

Sumber: Data Primer (2020).

Pada Tabel 2 dapat diketahui bahwa jenis tanaman didominasi oleh Sonokeling (Dalbergia latifolia) sebanyak 34 batang, Suren (Toona sureni) sebanyak 20 batang dan Alpukat (Persea americana) sebanyak 10 batang. Terdapat juga jenis pohon dengan jumlah paling sedikit salah satunya Flamboyan (Delonix regina) hanya terdapat satu batang saja. Berikut ini beberapa jenis pohon pada klaster plot di kawasan hutan lindung yang dikelola oleh HKm Beringin Jaya dapat dilihat pada Gambar 2.

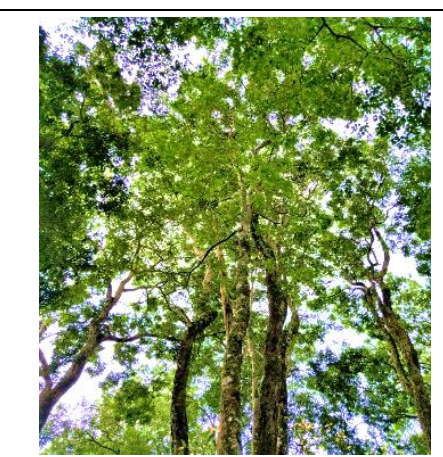

(a)

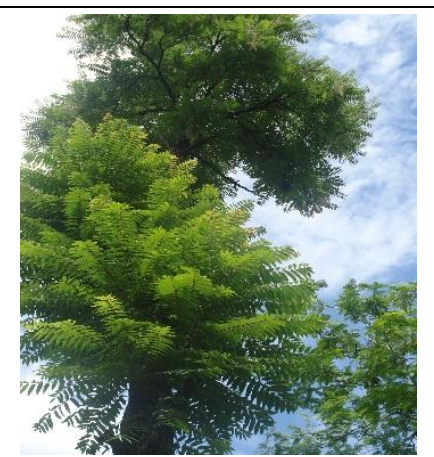

(b)

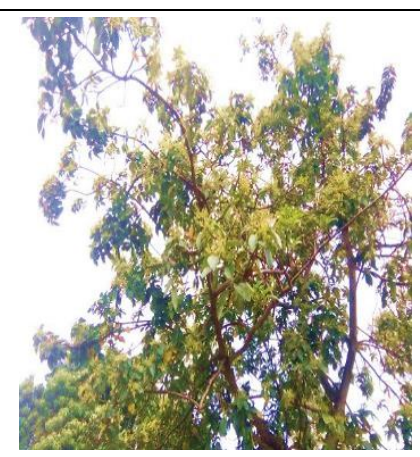

(c)

Keterangan: (a) pohon sonokeling (Dalbergia latifolia), (b) pohon suren (Toona sureni), (c) pohon alpukat (Persea americana)

Gambar 2. Beberapa jenis pohon di lokasi penelitian

Figure 2. Several types of trees in the research location 
Tabel 3. Nilai Skor Indikator Keanekaragaman Jenis Pohon

Table 3. Value of Species Diversity Indikator Scores

\begin{tabular}{cc}
\hline Nilai Skor & Kelas Keanekaragaman Jenis $\left(\mathbf{H}^{\prime}\right)$ \\
\hline 1 & $0,33-0,44$ \\
2 & $0,45-0,56$ \\
3 & $0,57-0,68$ \\
4 & $0,69-0,80$ \\
5 & $0,81-0,92$ \\
6 & $0,93-1,04$ \\
7 & $1,05-1,16$ \\
8 & $1,17-1,28$ \\
9 & $1,29-1,40$ \\
10 & $1,41-1,53$ \\
\hline
\end{tabular}

Sumber: Data Primer (2020).

Setelah memperoleh nilai keanekaragaman jenis, dilakukan penentuan nilai skor pada masing-masing klaster plot. Seperti yang disajikan pada Tabel 3. Data biodiversitas berupa keanekaragam spesies diperoleh dari pengambilan data secara langsung di setiap klaster plot. Data biodiversitas sangat dibutuhkan untuk dapat mengukur tingkat kelenturan suatu jenis dalam ekosistem tertentu (Safe'i et al., 2019).

Nilai skor tertinggi seperti pada Tabel 3 yaitu 10 dengan nilai kelas keanekaragaman jenis 1,41-1,53. Sedangkan, nilai skor terendah yaitu 1 dengan nilai 0,33-0,44. Nilai skor yang tinggi dan rendah dari indikator ekologis keanekaragaman jenis akan berpengaruh terhadap nilai akhir kondisi kesehatan hutan yang diperoleh. Semakin tinggi nilai skor yang diperoleh maka akan menunjukkan tingkat kesehatan hutan yang semakin tinggi (Safe'i \& Tsani, 2017). Nilai akhir kesehatan hutan diperoleh dari perhitungan perkalian antara nilai skor setiap klaster plot dengan nilai tertimbang. Nilai ambang batas status kesehatan hutan dan hasil nilai akhir kesehatan hutan ditampilkan pada Tabel 4 dan 5.

Tabel 4. Nilai Ambang Batas Keanekaragaman Jenis Pohon

Table 4. Tree Species Diversity Threshold Value

\begin{tabular}{ccc}
\hline No & Kategori & Kelas Nilai \\
\hline 1 & Baik & $2,53-3,60$ \\
2 & Sedang & $1,45-2,52$ \\
3 & Buruk & $0,36-1,44$
\end{tabular}

Sumber: Data Primer (2020).

Tabel 5. Nilai Akhir Kesehatan Hutan

Table 5. Forest Health Final Value

\begin{tabular}{ccc}
\hline Klaster Plot & $\begin{array}{c}\text { Nilai Akhir Kesehatan } \\
\text { Hutan (NKH) }\end{array}$ & Kategori \\
\hline 1 & 1,44 & Buruk \\
2 & 3,60 & Baik \\
3 & 0,36 & Buruk \\
4 & 0,36 & Buruk \\
5 & 3,60 & Baik \\
6 & 3,24 & Baik \\
\hline
\end{tabular}

Sumber: Data Primer (2020). 
Hasil menunjukkan bahwa kawasan hutan lindung yang dikelola oleh HKm Beringin Jaya memiliki tingkat keanekaragaman jenis pohon 50:50 yaitu 3 klaster plot menunjukkan komunitas vegetasi dengan kondisi lingkungan yang stabil dan 3 klaster plot menunjukkan komunitas vegetasi dengan kondisi lingkungan yang kurang stabil berdasarkan ShannonWhiener (Soerianegara dan Indrawan, 2005). Kategori kondisi kesehatan hutan diperoleh berdasarkan nilai akhir. Nilai akhir kesehatan hutan tertinggi di kawasan hutan lindung yang dikelola oleh $\mathrm{HKm}$ Beringin Jaya adalah sebesar 3,6 dan terendah 0,36. Hasil kategori kondisi kesehatan hutan ini menunjukkan dari 6 klaster plot masih ada 3 klaster plot dengan kategori buruk. Kategori buruk ini menandakan keanekaragaman jenis pohon yang rendah pada klaster plot tersebut. Maka masih diperlukan pengelolaan yang tepat dan intensif agar status kesehatan hutan di wilayah garapan dapat meningkat dan membaik. Berdasarkan Tabel 5 Kondisi kesehatan hutan yang paling sehat terdapat pada klaster plot 2 dan 5 yang memiliki nilai akhir tertinggi yaitu 3,60 dengan kategori baik. Sebaliknya, kondisi kesehatan hutan yang terburuk terdapat pada klaster plot 3 dan 4 dengan nilai akhir terendah yaitu 0,36. Dari hasil data yang diperoleh maka dapat disimpulkan bahwa kondisi kesehatan hutan di kawasan hutan lindung yang dikelola oleh $\mathrm{HKm}$ Beringin Jaya dikategorikan buruk sebanyak $50 \%$ dan dikategorikan baik sebanyak $50 \%$.

\section{KESIMPULAN DAN SARAN}

Hasil penelitian menunjukkan bahwa nilai akhir status kesehatan hutan dengan indikator keanekaragaman hayati (keanekaragaman jenis pohon) di lahan garapan $\mathrm{HKm}$ Beringin Jaya berada pada kriteria baik sebesar $50 \%$ pada klaster plot (2, 5 dan 6$)$ dan buruk sebesar $50 \%$ pada klaster plot (1,3 dan 4), sehingga kondisi pada saat ini status kesehatan hutan di HKm Beringin Jaya menunjukkan rata-rata berada pada kriteria sedang dan masih perlu dilakukan pengelolaan yang tepat dan intensif. Dengan demikian, kesehatan HKm Beringin Jaya yang berada pada KPHL Kota Agung Utara dapat dinilai menggunakan indikator keanekaragaman hayati dengan indikator keanekaragaman jenis pohon.

\section{UCAPAN TERIMA KASIH}

Terimakasih atas pendanaan Penelitian Terapan dari Direktorat Riset dan Pengabdian Masyarakat Deputi Riset dan Pengembangan Kementerian Riset, dan Teknologi / Badan Riset dan Inovasi Nasional sesuai dengan kontrak Penelitian Nomor : 179/SP2H/AMD/LT/DRPM/2020 dan UPTD KPH IX Kota Agung Utara atas izin lokasi penelitian.

\section{DAFTAR PUSTAKA}

Magguran, A.E. (1988). Ecological Diversity and Its Measurement. USA: Princeton University Press.

Mangold, R. (1997). Forest Health Monitoring: Field Methods Guide. USA: USDA Forest Service.

Nahlunnisa, H., Zuhud, E. A. M., \& Santosa, Y. (2016). Keanekaragaman spesies tumbuhan di areal nilai konservasi tinggi (nkt) perkebunan kelapa sawit Provinsi Riau. Jurnal Media Konservasi, 21(1), 91-98. 
Naisumu, Y.G., Yoseph, N.S. \& Ludgardis, L. (2018). Komposisi dan keanekaragaman jenis pohon di hutan lindung Lapeom Kabupaten Timor Tengah Utara. Jurnal Saintek Lahan Kering, 1(2), 4-7.

Nuraina, I., Fahrizal \& Prayogo, H. (2018). Analisa komposisi dan keanekaragaman jenis tegakan penyusun Hutan Tembawang Jelomuk di Desa Meta Bersatu Kecamatan Sayan Kabupaten Melawi. Jurnal Hutan Lestari, 6(1), 137-146.

Rahayu, G.A., Buchori, D., Hindayana, D. \& Rizali, A. (2017). Keanekaragaman dan peranan fungsional serangga pada area reklamasi pascatambang batubara di Berau, Kalimantan Timur. Jurnal Entomologi Indonesia, 14(2), 97-106.

Safe'i, R. \& Tsani, M.K. (2016). Kesehatan Hutan. Yogyakarta: Plantaxia.

Safe'i, R. \& Tsani, M.K. (2017). Penyuluhan program kesehatan hutan rakyat di Desa Tanjung Kerta Kecamatan Kedondong Kabupaten Pesawaran. Jurnal Pengabdian kepada Masyarakat, 1(1), 35-37.

Safe'i, R., Wulandari, C., \& Kaskoyo, H. (2019). Penilaian kesehatan hutan pada berbagai tipe hutan di Provinsi Lampung. Jurnal Sylva Lestari, 7(1), 95-109.

Safe'i, R., Erly, H., Wulandari, C. \& Kaskoyo, H. (2018). Analisis keanekaragaman jenis pohon sebagai salah satu indikator kesehatan hutan konservasi. Jurnal Perennial, 14(2), 32-36.

Safe'i, R., Febryano, I.G. \& Aminah, L.N. (2018). Pengaruh keberadaan gapoktan terhadap pendapatan petani dan perubahan tutupan lahan di hutan kemasyarakatan. Jurnal IImu-ilmu Sosial dan Humaniora, 20(2), 109-114.

Safe'i, R., Hardjanto, Supriyanto \& Sundawati, L. (2015). Pengembangan metode penilaian kesehatan hutan rakyat sengon. Jurnal Penelitian Hutan Tanaman, 12(3), 175-187.

Safe'i, R., Indriani, Y., Darmawan, A. \& Kaskoyo, H. (2019). Status pemantauan kesehatan hutan yang dikelola oleh kelompok tani hutan shk lestari: Studi kasus kelompok tani hutan karya makmur I Desa Cilimus, Kecamatan Teluk Pandan, Kabupaten Pesawaran, Provinsi Lampung. Jurnal Silva Tropika, 3(2), 185-198.

Soerianegara, I. \& A. Indrawan. (2005). Ekologi Hutan Indonesia. Bogor: IPB Press.

Supriyanto, Stolte, K.W., Soekotjo \& Gintings, A.N. (2001). Forest Health Monitoring to Monitor The Sustainability of Indonesian Tropical Rain Forest. Bogor: SEAMEOBIOTROP.

Undang-undang No. 41 tahun 1999 tentang Kehutanan.

United States Development Agency-Forest Service. (1999). Forest Health Monitoring: Field Methods Guide. USA: Da Forest Service Research Triangle Park.

Winarni, S., Yuwono, S.B. \& Herwanti, S. (2016). Struktur pendapatan, tingkat kesejahteraan dan faktor produksi agroforestri kopi pada kesatuan pengelolaan hutan lindung Batutegi. Jurnal Sylva Lestari, 4(1), 1-10.

Wulandari, C. (2010). Studi persepsi masyarakat tentang pengelolaan landscape agroforestri di sekitar sub das Way Besai Provinsi Lampung. Jurnal IImu Pertanian Indonesia, 15(3), 137-140. 